\title{
Invertebrates, Marine
}

National Cancer Institute

\section{Source}

National Cancer Institute. Invertebrates, Marine. NCI Thesaurus. Code C14360.

Animals without a backbone that live in the ocean 